\title{
Adjectives in Likpakpaln (Konkomba): Structural and Areal-Typological Aspects
}

\author{
Abraham Kwesi Bisilki \\ University of Hong Kong \& \\ University of Education, \\ Winneba, Ghana
}

\section{Kofi Yakpo}

University of Hong Kong

\section{Abstract}

Likpakpaln is a little-described Mabia (Gur) language of northern Ghana. Drawing on primary data, this first study of adjectives in Likpakpaln concludes that the language has a small, closed adjective class of about 20 members that shares grammatical properties with nouns and verbs to varying degrees. Contrary to what is the case in other Mabia languages, Likpakpaln adjectives lack inherent class markers. We identify three types of adjectives, distinguishable from nouns and verbs on morpho-syntactic and semantic grounds. Type 1 items lean towards nouns and never function as predicates of verbal clauses. Type 2 consists of one item, possibly a loan, and appears in a predicate adjective construction typical of languages with large adjective classes. Type 3 adjectives lean towards verbs and may form the predicate of verbal clauses. An understanding of Likpakpaln adjectives can contribute to refining our current knowledge of the genetic and typological position of Likpakpaln in the Mabia family.

Keywords: Likpakpaln; Konkomba; adjective; noun; verb; typology; derivation; Gur; Mabia; Ghana 


\section{Introduction}

The debate over the universality of the adjective category seems to have established that every language has adjectives (Ameka 2001; Dixon 2010a, 73; Nsoh 2011, 45-46; Musah 2018, 118). In this article, we analyse primary data from Likpakpaln, a littleknown Mabia (Gur) language of the Niger-Congo phylum, spoken mainly in northern Ghana (see Bodomo 1997, vii, for the use of "Mabia" instead of the older label "Gur"). Our analysis of Likpakpaln relies substantially on Dixon's (1977; 1982a; 2010a) typological framework and also takes other typologically oriented approaches to adjectives into account (e.g., Bhat 1994; Croft 1991).

A key concern of this article is to affirm the existence of an adjective class in Likpakpaln and to describe and analyse its features. We concentrate on identifying the morphological, syntactic and semantic properties of the Likpakpaln adjective as a distinct lexical and syntactic category. Furthermore, we seek to understand the most salient typological features of the adjective class in Likpakpaln. In doing so, we aim to provide future work with a firmer basis on which to rest typological generalisations in this regard.

We argue that Likpakpaln has a closed class of about 20 adjectives. Cross-linguistically, Likpakpaln belongs to the Type $c$ languages of Dixon's (2010a, 63) typology. This implies that adjectives assume linguistic characteristics of both verbs and nouns (see section 4). Likpakpaln adjectives lack class affixes in noun-adjective attributive constructions. From a genealogical and typological perspective, Likpakpaln therefore differs sharply in its morphological agreement pattern from other Mabia languages of Ghana (e.g. Dagbani, Dagaare, Kusaal and Gurenc). Agreement with a reference noun, and hence morphological marking of adjectives, is also a widespread feature in other non-Mabia Niger-Congo languages of the Kwa and Bantu families (e.g. Segerer 2008; Mpofu 2009).

This article is structured as follows: Section 2 provides an overview of the state of research on Mabia and Likpakpaln. Section 3 describes the data collection and analysis methods employed. In section 4 we discuss the theoretical framework. Section 5 describes some relevant aspects of Likpakpaln nouns and verbs and how they relate to adjectives. In section 6 , we turn to the description and analysis of Likpakpaln adjectives as attributive modifiers (6.2), copula complements (6.3), and as predicators in verbal clauses (6.4). Section 7 places the structural properties of Likpakpaln adjectives within the broader typological context and section 8 concludes this article.

We employ the standard Likpakpaln orthography, which either follows IPA conventions (e.g. $\mathrm{y}=/ \mathrm{y} /, \mathrm{kp}=/ \widehat{\mathrm{kp}} /, \mathrm{o}=/ \mathrm{o} /$ ) or correlates with the corresponding English orthographic conventions in the case of the following graphemes: $j=/ \widehat{d z} /, c h=/ \widehat{t} /, y=/ j /$. Likpakpaln makes use of lexical and grammatical tone and probably features three phonemic tones, i.e. high, mid, and low. We do not, however, mark tone in this study since we have not yet concluded our analysis of the tone system of Likpakpaln. A thorough understanding 
of the tone system would, without doubt, have enriched the present study but our preliminary analysis of tone does not seem to alter the main findings of this study in a significant way.

\section{The State of Research on Mabia and Likpakpaln}

The Mabia languages of West Africa are among the most poorly researched African languages (Cahill 2007, 5; Naden 1988, 12). Likpakpaln, spoken in the Republic of Ghana, is particularly under-researched compared to other languages of the Mabia grouping in the region. Unlike Mabia languages like Dagaare, Dagbani, Gurene, and Kasem, Likpakpaln is not institutionally sponsored or recognised as a language of instruction in Ghana (see Hasselbring 2006; Schwarz 2009). This is unfortunate given that the Likpakpaln native speaker population in Ghana alone is estimated at a significant figure of 831000 (Simons and Fennig 2017). The same source also provides a figure of 84700 speakers in neighbouring Togo.

The adjective category in Likpakpaln arouses interest for various reasons. The first is to gain a better understanding of the general structure of the language, given the lack of descriptive work. With regard to lexical categories and their formal manifestations, for instance, the only references remain Adouna (2009), Bisilki and Akpanglo-Nartey (2017), and Miehe, Reineke and Winkelmann (2012). Adouna (2009), however, covers the Naware dialect of Togo, which displays marked structural and sociolinguistic divergence from the Ghanaian varieties. Bisilki and Akpanglo-Nartey (2017) solely treat the nominal morphology of Likpakpaln. Adouna (2009, 258-263) provides a few examples illustrating the attributive and predicative uses of adjectives in Likpakpaln, but only within the general context of his sketch grammar, and so does not answer the questions addressed here. Furthermore, Adouna does not provide typological observations on the adjective class in Likpakpaln.

A further motivation to look at adjectives in Likpakpaln stems from the fact that linguists continue to grapple with defining clear-cut boundaries for the adjective category. Musah (2018) and Olawsky $(1999 ; 2004)$ suggest that adjectives are a distinct class in Mabia. However, the criteria proposed are vague. Their analyses blur differences between semantic properties, morphological features, and syntactic distributions of the expressions classified as adjectives, which tend to overlap greatly with verbs, nouns or both. The analyses therefore do not provide clear semantic and morphosyntactic evidence for the distinction between adjectives and other word classes. In this article, we therefore aim to provide a clearer analysis of the adjective class in Likpakpaln, and in doing so, present new data on the status of adjectives in Mabia. 


\section{Data for the Study}

The data for the present analysis is mainly from the Saboba district in northern Ghana, a traditional Likpakpaln-speaking area. Saboba is well known for its high concentration of Bikpakpaam (speakers of Likpakpaln) in Ghana (see Hasselbring 2006; Maasole 2006; Tait 2018). Likpakpaln speakers are, however, also indigenous to other parts of Ghana. The main method of data collection for this study was elicitation via an adjective wordlist, based on Dixon (2010a, 73-76), conducted between December 2018 and January 2019. Elicitations were cross-validated and complemented through semi-structured interview sessions with two native speakers from Saboba. These two speakers (male and female) are both in their late 40s and have spent most of their lives in their traditional home in Saboba.

There is some degree of multilingualism in the Saboba area due to the presence of other ethnic groups such as the Moshi, Ewe, Chakosi (also known as Anufo), Dagomba, and Hausa (Saboba District Assembly 2018, 4). Nonetheless, Likpakpaln remains the dominant everyday language in Saboba communities. Other linguistic groups in the area constitute minorities vis-à-vis Likpakpaln speakers. Although the motivation to learn to speak Likpakpaln by non-Bikpakpaam is generally rather low, the linguistic minorities in the Saboba area still acquire some level of proficiency in Likpakpaln in order to meet basic interactional needs. The Saboba district is bounded in the south-west by the Yendi Municipal District, a major traditional area of Dagbani speakers (Olawsky 2004, 127). Yendi is some $54 \mathrm{~km}$ from Saboba. Dagbani is a minority language in the Saboba district but constitutes a major language in northern Ghana. Hence, Likpakpaln speakers in the area tend to be bilingual in Dagbani, and - provided a certain level of formal education has been attained-in Ghana's official language, English. Finally, we should add that "Konkomba" is the term generally used as an exonym by non-Bikpakpaam Ghanaians to refer to both Likpakpaln and its speakers.

\section{Identifying Adjectives: Theoretical and Language-Specific Aspects}

The treatment of adjectives as a class in their own right has long been a source of debate in linguistics. The controversy has even led to some linguists changing their persuasions. Dixon (2010a, 73), making reference to his earlier position (Dixon 1977; 1982b), admits his previous conviction that adjectives did not form an independent lexical class. Nevertheless, following support from subsequent work in favour of the recognition of the adjective class (see the contributions in Dixon and Aikhenvald 2004), a comprehensive framework for the analysis of adjectives is offered by Dixon (2010a). It is mostly with recourse to this framework that the present analysis proceeds. We also draw on Pustet's (2003) study of semantic universals governing the distribution of copulas as well as typological and descriptive accounts of adjectives in African languages (e.g. Welmers 1973; Segerer 2008; Mpofu 2009). 
Languages vary in terms of the size of their adjective classes. On the one end of the spectrum, we find large and open adjective classes. On the other end, we find languages with closed adjective classes containing very few members. Dixon (2010a) suggests that a language with a large adjective class will normally have hundreds of members, as is the case with English and other languages of Europe. Conversely, a language with a small adjective class may have below five members, as in the case of Yimas (Lower Sepik family, New Guinea; see Foley 1991) and Kham (Tibeto-Burman, Nepal; see Watters 2002). In a similar vein, Segerer $(2008,1)$ observes that African languages with closed adjective classes have member numbers ranging from 2 to more than 100, citing the case of Dagbani with 101 adjectives and Kele (Niger-Congo, Bantu, DR Congo) with only 2 adjectives.

A second dimension of cross-linguistic variation concerns grammatical properties, specifically the extent to which adjectives overlap formally with the verbal and the nominal categories in a language. Describing these properties requires granular semantic and morpho-syntactic analyses across a variety of features. Dixon (2010a, 77-90) lists a number of heuristic tools to distinguish adjectives from verbs on the one hand and from nouns on the other. Broadly, these concern the distributional potential and morphological possibilities of adjectives within the verb or noun phrase, the potential for adverbialisation, and use in comparative constructions.

The presence or absence of copulas in predications can also serve as a key diagnostic in determining the existence of an adjective class. Drawing on the four semantic parameters of dynamicity, transience, transitivity, and dependency, Pustet (2003) seeks to identify the universal principles that govern the distribution of copulas in nominal, adjectival, and verbal predications through the inherent meaning of the lexical items with which they can combine.

Dixon divides languages into four types with respect to the overlap of adjectives with verbs and nouns. So-called Type $a$ languages have adjectives that are similar to verbs. Type $b$ has adjectives with nominal properties. Type $c$ refers to languages whose adjectives share features with both verbs and nouns. In Type $d$ languages, there are no overlaps with either the verbal or the nominal category.

In the Mabia and Kwa languages for which there is some data, there is no unanimity on the gradations of overlap between adjectives on the one hand and nouns and verbs on the other. For instance, Dagbani (Mabia) adjectives are coterminous with nouns insofar as adjectives can be marked by class affixes for singular and plural numbers. At the same time, they are distinct from nouns in as much as adjectives can neither serve as NP heads nor take determiners (Olawsky 2004). In Logba (Kwa, Ghana-TogoMountain), a basic distinction between nouns and adjectives is that nouns precede adjectives in phrase structure. Equally, nouns have inherent class markers, while adjectives do not (Dorvlo 2008, 98-99). This difference is also found in Likpakpaln: Nouns have obligatory noun class affixes while adjectives lack them. The large range 
of language-specific differences between adjectives, nouns, and verbs supports claims that no two languages are the same in relation to a feature (Dixon 2010b, 9).

Furthermore, Dixon (2010a, 73-76) proposes seven universal semantic classes of adjectives. These are dimension, age, value, colour, physical property, human propensity, and speed. These dimensions are, in turn, segmented into Type A (dimension, age, value, and colour concepts) and Type B (physical property, human propensity, and speed) adjectives. Type A adjectives are seen to belong to the core adjective classes (Welmers 1973; Segerer 2008; Dixon 2010a). Furthermore, adjectives are classified into underived and derived types (e.g. Dorvlo 2008, 95; Mpofu 2009, 5758). Derivation occurs when adjectival words are created from other lexical classes such as nouns or verbs. A language in which there is adjective derivation in this sense is described as having an open adjective class system. The term "primary adjectives" has also been adopted to designate underived adjectives (Segerer 2008, 3).

Closed adjective systems are said to predominate in African languages (Welmers 1973, 250; Dorvlo 2008; Segerer 2008). Likpakpaln, too, has a closed adjective system and hence conforms to the "African" type. Using the heuristic methods proposed by Dixon (2010a, 77-90) and Pustet (2003), we identified six diagnostic criteria of adjectivehood in Likpakpaln:

(1) Likpakpaln adjectives can be distinguished from nouns in that they are morphosyntactically dependent and are only used in collocation with head nouns. To use an adjectival word in isolation requires nominalisation or verbalisation of the form concerned. These processes, however, also indicate the structural overlaps of adjectives with nouns and verbs.

(2) Adjectives differ morphologically from nouns by lacking their own class markers.

(3) An adjective may not head an NP. Nouns, on the other hand, may occur both as heads and modifiers of NPs.

(4) Nominal modifiers precede the head noun while adjectival (attributive) modifiers follow the head noun.

(5) The largest group of adjectives in Likpakpaln (which we refer to as Type 3; see Table 1 in section 7) can occur as ambitransitive predicates in verbal clauses. Save for a single instance (/t $\mathrm{fam} /$ chain "clean"), adjectives may not occur in the complement position of the existential/locative or identity/equative copula. Likpakpaln nouns do, however, appear as complements of the two copulas.

(6) Semantically, adjectives denote property concepts while nouns may naturally have a broader range of denotations. 
The six criteria above are expounded in more detail in the sections to follow. In view of the overlaps between the syntactic categories of nouns, verbs, and adjectives mentioned above, we briefly characterise Likpakpaln nouns and verbs in sections 5.1 and 5.2 before moving on to adjectives in section 6 .

\section{Nouns and Verbs in Likpakpaln}

This section discusses some fundamental morphological, syntactic and semantic features of Likpakpaln nouns and verbs. We consider this to be relevant for an understanding of how adjectives relate to nouns and verbs in the language. Section 5.1 treats nouns and 5.2 highlights relevant aspects of verbs.

\subsection{The Noun}

Nouns, verbs, and adjectives can share syntactic and semantic characteristics in various ways and to varying degrees in Type $c$ languages (see Dixon 2010a). As a case in point in Mabia, adjectives and nouns overlap so extensively in Moore (Ghana and Burkina Faso) that Olawsky $(2004,44)$ considers it plausible to regard adjectives as forming a class with nouns. Such evidence of relations between nouns and adjectives in other languages of the Mabia family calls for a description of some fundamental features of nouns when one seeks to examine the adjective category in Likpakpaln.

Likpakpaln nouns consist of a stem and affix(es). Affixes are obligatory and instantiate class and number features. A noun may have a prefix or a suffix, or both simultaneously, hence the characterisation of Likpakpaln as a "bilateral noun class language" (Bisilki and Akpanglo-Nartey 2017; Miehe et al. 2012). Bilateral noun classes are a feature of the Mabia languages and are attested in Dagaare (Dakubu 2005, 42), Dagbani (Olawsky 1999, 71), Gurenc (Nsoh 2002, 2), and Kusaal (Musah 2018, 81-82). However, unlike in Likpakpaln, adjectives in these other Mabia languages also bear morphological markers of their own, for example when they occur as citation forms. In Dagaare for instance, we have the forms: prl-aa (white-SG) and prel-I (white-PL). According to Dakubu $(2005,47)$, the suffixes mark the above adjectives as singular or plural and also as belonging to noun class 6 in Dagaare.

The distribution of co-occurring prefixes and suffixes is highly irregular in Likpakpaln. In some instances, a noun in the singular has both a prefix and a suffix, but one of the two affixes is dropped for plural formation (1). In other instances, the reverse holds and a singular noun that only has a prefix takes both a suffix and a prefix in the plural (2):

$\begin{array}{ll}\boldsymbol{l i} \text {-bii-l } & \boldsymbol{y} \boldsymbol{i} \text {-bii } \\ \text { CL.SG-breast-CL.SG } & \text { CL.PL-breast } \\ \text { "breast" } & \text { "breasts" }\end{array}$


(2)

$\begin{array}{ll}\boldsymbol{u} \text {-pii } & \boldsymbol{b i} \text { - } p i i-\boldsymbol{b} \\ \text { CL.SG-woman } & \text { CL.PL-woman-CL.PL } \\ \text { "woman" } & \text { "women" }\end{array}$

To make matters more complicated, other nominals in Likpakpaln do not take any affixes at all when in the singular. Members of this group frequently include loans and kinship terms (Bisilki and Akpanglo-Nartey 2017, 32), as in (3) and (4) respectively. The pluralisation of such nouns is achieved by the suffixation of either -mam or -tiib alone.

$$
\begin{array}{ll}
\text { loor } & \text { loor-tiib } \\
\text { car } & \text { car-CL.PL } \\
\text { "car" } & \text { "cars" }
\end{array}
$$

(4) na

$$
\begin{array}{ll}
\text { na } & \text { na-tiib } \\
\text { mother } & \text { mother-CL.PL }
\end{array}
$$$$
\text { "mother" "mothers" }
$$

Nouns function as heads and modifiers in the Likpakpaln NP. The modifier role of nouns has been described for some Mabia languages including Dagaare (Dakubu 2005, 47-48), Dagbani (Olawsky 1999), and Kusaal (Musah 2018), but not yet in sufficient detail for Likpakpaln. Unlike nominal modifiers, which are preposed, adjectival modifiers are postposed to the head noun in the Likpakpaln NP (see 6.2 for details). When heading an NP, a noun can take determiners (5) and other modifying elements such as a numeral (6):

$\begin{array}{llllll}{\left[\begin{array}{llll}S i & \boldsymbol{u}-\boldsymbol{j} \boldsymbol{a} & \boldsymbol{w e i} & \text { le }\end{array}\right]_{\mathrm{NP}}} & m & \text { ban. } \\ \text { 2SG.INDP } & \text { CL.SG-man } & \text { DEM } & \text { FOC } & \text { 1SG } & \text { search } \\ \text { "You are the man I am looking for." } & & \end{array}$

$$
\begin{array}{llll}
\text { Soja-tiib } & \text { daa } & {[\text { yi-na-yil }} & \text { yi-lei. }]_{\mathrm{NP}} \\
\text { soldier-CL.PL buy } & \text { CL.PL-cow-head-CL } & \text { CL-two } \\
\text { "Soldiers have bought two cow heads." } &
\end{array}
$$

Two issues are noteworthy with respect to (6). The preposed nominal modifier, $u$-na (cow) loses its own noun class marker $u$ - and forms a morphological compound with the head noun -yil (head). The head noun -yil then lexically determines the plural affix for the entire compound, which is $\eta i$-. This gives $\eta i-n a-y i l$ (cow heads). The noun class marker $\eta i$ - of the head noun is also imposed on the following numeral modifier -lei (two) by grammatical agreement, rendering gi-lei. Accordingly, a change in the head noun results in a corresponding change of the noun class marker(s), as in (7):
(7) $\boldsymbol{i}$-na
i-lei.
CL.PL-Cow CL-two
"two cows." 
Nouns can fill copula complement slots in Likpakpaln. The copula complement function is one of the parameters along which nouns and adjectives can be differentiated in Likpakpaln (see 6.3). A lexical noun can follow the equative/identity copula ye, as in (8). The complement slot of the locative copula $b i$ is reserved for adjuncts, as in (9a), hence the ungrammaticality of (9b):

$$
\begin{array}{llll}
\text { U-na } & \boldsymbol{y} \boldsymbol{e} & k i-w \jmath k u-k & l a . \\
\text { CL.SG-cow } & \text { COP } & \text { CL.SG-animal-CL.SG } & \text { FOC } \\
\text { "A cow is an animal." } &
\end{array}
$$

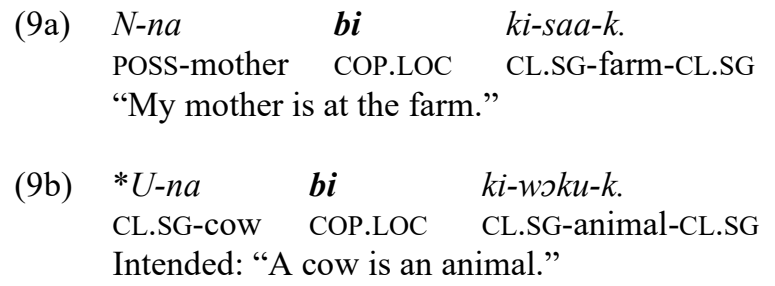

\subsection{The Verb}

Apart from a core of lexically transitive verbs, Likpakpaln verbs are ambitransitive, i.e. they participate in a transitivity alternation. For example, the verb laa (laugh) may appear in an intransitive (10) and a transitive (11) clause alike. Transitive uses may also involve cognate objects, as in (12):

(10) Konja laa.

NAME laugh

"Konja laughed."

(11) Konja laa $\boldsymbol{u}$-jo.
NAME laugh CL.SG-friend
"Konja laughed at his friend."

(12) Konja laa ti-laa-(r).

NAME laugh CL-laughter-CL

"Konja laughed (laughter)."

We will shortly see that Likpakpaln adjectives (of Type 3) are also ambitransitive when they appear in verbal slots (see 6.4). Nonetheless, this category of adjectives is morphosyntactically distinct from primary verbs. The difference between verbalised adjectives and verbs proper is also discussed in 6.4. In the remaining sections, we examine Likpakpaln adjectives and, amidst other typological considerations, point out their similarities to and differences from the characteristics of nouns and verbs identified in 5.1 and 5.2. 


\section{Adjectives in Likpakpaln}

We now discuss the morphology and syntax of adjectives in Likpakpaln, focusing on their structural-functional differences vis-à-vis other modifiers, nouns, and verbs. Importantly, Likpakpaln has a closed adjective class which cannot be extended by derivation (6.1). Likpakpaln adjectives differ from nouns on two structural accounts. First, adjectives lack inherent noun class markers. Likpakpaln adjectives are morphologically (and referentially) non-autonomous. Using an adjectival root requires placing it in juxtaposition to another word or in morphological dependence of an antecedent noun (6.2). Second, unlike nouns, adjectives do not occur as copula complements, with a single exception (6.3). The distinction between verbs and adjectives in Likpakpaln is less clear cut than that between nouns and adjectives. This aligns with cross-linguistic observations that adjectives are grammatically and semantically more similar to verbs than they are to nouns (Bhat 1994, 43). A minority of 6 adjectives (Types 1 and 2; see Table 1) does not appear as predicates of verbal clauses. However, Type 3 adjectives, which make up the majority in the language, may be used as ambitransitive verbs. They may thus form the predicative nucleus of verbal clauses just like any other verb in Likpakpaln (6.4).

\subsection{Adjective Derivation}

Adjective derivation is traditionally seen as the formation of adjectives from other word classes through a morphological or syntactic process (Mpofu 2009, 57-58; Segerer $2008,3)$. Adjectives form a closed class in Likpakpaln, so there is no possibility of extending the adjective class by derivation. Conversely, adjectives may be seen as lexical sources for the nominal and verbal lexical categories in Likpakpaln. First, all Type 3 adjectives can constitute the predicate of verbal clauses by themselves; they do not need to appear as complements of copulas. Second, adjectives may be seen as a source of nouns via the formation of adjectival nouns. Adjective nominalisation is, however, restricted to Type 1 and Type 3 adjectives. Adjectives may only occur in isolation if they bear the noun class affix of a discourse-antecedent noun (see [13] and [14]). Accordingly, an adjective can be cited by attaching a noun class affix to it, which is then in class-number agreement with an antecedent or discursively implied head noun (see Bisilki and Akpanglo-Nartey 2017; Miehe et al. 2012). When this happens, the adjective concerned assumes nominal qualities. The use of u-sakpiin in (13) presupposes a singular animate antecedent noun like $u$-nii (person) or $u$-nyii (crocodile). Similarly $b i-b o m b o-m$ (14) necessarily refers to an animate plural noun like bi-ni-b (people) or bi-pii-b (women).

$\boldsymbol{u}$-sakpiin

CL.SG-big

"big one"

\footnotetext{
bi-bombo-m

CL.PL-black-CL.PL

"black ones"
} 
Once it carries an affix, an adjectival noun can perform any argument function or semantic role, and occupy the copula complement slot assignable to other, more prototypical nouns. In (15) and (16), the adjectival noun is a copula complement. It functions as a fronted object in (17) and as the theme object of a verb of possession in (18).

$\begin{array}{lllll}\text { Li-dacha-l ngbaan } & \text { popun } & \text { ye li-sakpen-l } & \text { la. } \\ \text { CL.SG-house-CL.SG that } & \text { ADV COP CL.SG-big-CL.SG } & \text { EMPH } \\ \text { "That house is really big." Lit. "That house is (of) bigness." } & \end{array}$

$\begin{array}{lllll}\text { Ki-ju- } k & \text { ngbaan } & \boldsymbol{y e} & \boldsymbol{k i} \text {-bamoy } & \text { la. } \\ \text { CL.SG-knife-CL.SG } & \text { that } & \text { COP } & \text { CL.SG-real } & \text { EMPH } \\ \text { "That knife is a real/good/proper one." } & & \end{array}$

(17) Bi-sakpem bemina le ti ban ti daa. CL.PL-big DEM FOC we want SID buy "It is these big ones that we want to buy."

$\begin{array}{llll}\text { (18) } & \text { N-tiwa } \quad k p a \quad \text { bi-mamam } & \text { bi- } y m u \\ \text { CL-uncle } & \text { have } & \text { CL.PL-red } & \text { CL.PL-five } \\ \text { "My uncle has five red ones." } & \end{array}$

From a genetic-typological perspective, this sets the behaviour of Likpakpaln adjectives apart from those of other (Ghanaian) Mabia languages like Dagabani (Olawsky 1999; 2004), Dagaare (Bodomo 1997; Dakubu 2005), Kusaal (Abubakari 2018; Musah 2018) and Guren (Atintono 2013). In these languages, adjectives bear their own noun class markers comparable to those of nouns (cf. 5.1). Given the wide currency of adjectival class markers in Mabia, it is possible that Likpakpaln adjectives had such markers of their own, but lost them in the course of diachronic change. But this remains for future investigation.

In the following three subsections, we turn to further, more specific characteristics of adjectives in NPs (6.2) and copula clauses (6.3), and as a predicator in verbal clauses (6.4)

\subsection{The Adjective as an Attributive Modifier}

In the Likpakpaln NP, an adjectival modifier is positioned immediately after the head noun, even if other modifiers are present in the structure. The adjectival modifier forms a noun-adjective (N-A) compound with the head noun. The use of such attributive compounds is a general feature in Mabia (cf. Dakubu 2005; Musah 2018). The noun class affix of the nominal head assumes scope over the whole N-A compound, as shown in (19).

(19) Konja yor ti-kur-nyuun.

NAME lift CL.SG-metal-heavy

"Konja lifted a piece of heavy metal." 
Where the head noun involved is a member of a class that lacks an affix (i.e. class 1a in Likpakpaln), the corresponding N-A compound does not have an affix either, as with the kinship noun na (mother) in (20).

(20) Na-nyaan aa-nan waa-bo.

mother-good NEG-hate POSS-child

"A good mother does not hate her child."

The headship of nouns can be demonstrated as follows in N-A attributive constructions. Sentence (19) above remains grammatical when the adjective nyuun (heavy) of the N-A compound is deleted as in (21a), but not if the head noun is deleted, see (21b):

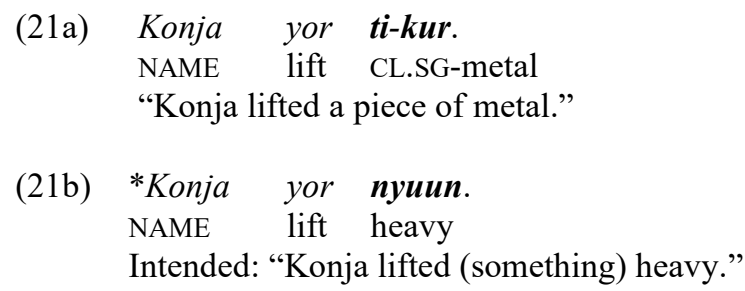

The structural pattern observed for N-A attributive compounds also holds for lexicalised $\mathrm{N}-\mathrm{A}$ compounds, as in (22) and (23). Lexicalised N-A compounds can have varying degrees of metaphorical associations with their components ranging from more to less transparent (cf. Agyekum 2013 for Akan).

$\begin{array}{llll}\text { U-ja } & \text { wei } & \text { kpa } & \text { n-yi-puan. } \\ \text { CL.SG-man } & \text { DEM } & \text { have } & \text { CL.SG-head-strong }\end{array}$

"This man is haughty/headstrong."

\section{(23) Konja kpa li-yi-muan-l. \\ NAME have CL.SG-head-sweet-CL.SG \\ "Konja is (born) lucky."}

Nominal modifiers differ from adjectival ones in their positioning within the NP. Unlike the adjectival modifier, which is postposed, the nominal modifier is preposed to the head noun. With regard to morphology, nominal modifiers are, however, no different from adjectival modifiers. Both types of modifiers occur stripped of noun class markers in modificational constructions. The compound takes on the affix of the head noun, with this affix attaining scope over the entire construction. Compare the noun-noun $(\mathrm{N}-\mathrm{N})$ compounds in (24) and (25):

$\begin{array}{lll}\text { (24) } \text {-yoob; } & t i-j i i-r & t i-\boldsymbol{y} \text {-jii-r } \\ \text { CL.SG-goat } & \text { CL.SG-food } & \text { CL.SG-goat-food-CL.SG } \\ \text { "goat"; } & \text { "food" } & \text { "goat food" }\end{array}$




$\begin{array}{lll}\text { li-ja-l; } & \begin{array}{l}\text { cheechee } \\ \text { bicycle }\end{array} & \text { li-cheechee-ja-l } \\ \text { CL.SG-SG-bicycle-seat-CL.SG } \\ \text { "seat"; } & \text { "bicycle" } & \text { "bicycle seat" }\end{array}$

There is further morphosyntactic evidence for the adjectival status of the property items covered in (19)-(25). The distribution of adjectives in nominal structures not only differs from that of modifier nouns, it also deviates from that of non-adjectival stative or resultative verbs. The latter are not found in N-A attributive compounds at all (26), and instead occur as verbal predicates in relative clauses if an antecedent nominal is to be modified (27).

$$
{ }^{*} N-t i \quad d a a \text { cheechee-bi. }
$$

POSS-father buy bicycle-spoil

Intended: "My father bought a broken bicycle."

$\begin{array}{lllll}N-t i \quad d a a & \text { cheechee } \quad \text { u } & b i & n a . \\ \text { POSS-father buy bicycle REL spoil } & \text { DEF } \\ \text { "My father bought a bicycle that's spoilt/broken." }\end{array}$

Adjectives also differ from numeral modifiers. The latter follow the head of the NP and the adjectival modifier. Just like adjectives, numerals have no noun class affixes of their own. Unlike the adjective in an N-A compound, the numeral does not, however, occur bare of a noun class marker. Numerals are not incorporated into the NP but rather occur as independent words in the NP. They are, therefore, subjected to agreement marking and take on the noun class affix of the preceding head noun. In (28), the colour adjective mam (red) is postposed to the head noun -saps (lady) and incorporated into the N-A compound bi-saps-mam (fair ladies). The numeral -taa (three) however takes its own noun class marker $b i$-, in agreement with the head noun bi-saps (ladies):

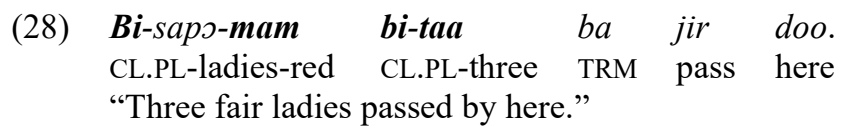

In sum, we note that modifier adjectives and modifier nouns form compounds with head nouns, but they differ in constituent order. Numeral modifiers, in turn, follow the NP like adjectival modifiers but do not form attributive compounds and take the noun class affix of the head noun. Modifier adjectives also differ from stative or resultative verbs in that they can occur in N-A compounds.

\subsection{The Adjective as a Copula Complement}

Likpakpaln adjectives do not lend themselves to use as adjectival complements to either of the two Likpakpaln copulas ye (identity/equative) or $b i$ (locative). As a result, the copula clause in (29) is ungrammatical. 
Chain (clean) is the only adjective that can function as an adjectival complement to either copula without any appreciable difference in meaning between the two (30). Chain can also occur in N-A attributive constructions (31). But attributive constructions involving chain tend to be more idiomatic than literal in meaning as reflected in the translation of (31).

$\begin{array}{lll}\text { U-yoob } \quad \boldsymbol{y e} / \boldsymbol{b i} & \text { chain } & \text { pam. } \\ \text { CL.SG-goat COP/COP.LOC } & \text { clean } & \text { IDEO } \\ \text { "The goat is really clean." } & & \end{array}$

$\begin{array}{llll}\text { U-ja wei aa-ye uni-chain } & u \text {-ba. } \\ \text { CL.SG-man DEM NEG-COP person-clean } & \text { CL.SG-one } \\ \text { "This man is not someone decent." } & \end{array}$

Unlike some other Likpakpaln adjectives, chain cannot be nominalised when it occupies a copula complement slot. Hence (32) is ungrammatical because it is nominalised via agreement with the subject $u$-sapuan (young lady). Contrast this with adjectives like sakpen (big) in (15) and bamsy (real) in (16), which have to be nominalised in order to fill the complement slot.

$$
\begin{aligned}
& \text { *U-sapuan ye u-chain. } \\
& \text { CL-young.lady COP CL-clean } \\
& \text { Intended: "This young lady is clean/neat." }
\end{aligned}
$$

The peculiar distribution of chain suggests that it may have entered Likpakpaln as a loan word from an unknown source. Code-switched Akan and English adjectives, for example, are also incorporated into Likpakpaln clauses as copula complements. Compare the Akan and English adjectives bone (bad) and clever in (33).

$$
\begin{array}{llll}
\text { Li-sibil ye bone } & \text { la. } \\
\text { CL.SG-insult } & \text { COP } & \text { bad } & \text { FOC } \\
\text { "Insult(ing) is bad." } & &
\end{array}
$$

$\begin{array}{llll}\text { U-bo } & \text { wei } & \text { ye } & \text { clever. } \\ \text { CL.SG-child DEM } & \text { COP } & \text { clever } \\ \text { "This child is clever." } & & \end{array}$

There is areal evidence that languages with a weak adjective-verb distinction make use of copula clauses as a template for the integration of borrowed or code-switched adjectives from languages with large adjective classes (see Meechan and Poplack 1995 for Wolof-French; Yakpo 2009 for Pichi-Spanish; Van den Berg et al. 2017 for Ewe-English/French, Akan-English, and Sranan-Dutch). We return to the divergent 
distribution of chain in section 7 where we address the broader distribution of adjectives in Likpakpaln.

When any adjective other than chain is used to predicate a property, it may, therefore, only occur as an ambitransitive verb in a verbal clause, as shown in the next subsection.

\subsection{The Adjective as a Verbal Predicate}

As mentioned earlier (6.1), Likpakpaln adjectives of Type 3 (see Table 1) can be considered as a source of verb derivation when they are used in the syntactic slot of a verbal predicate. In such instances, the verbalised adjective behaves like any other ambitransitive verb, and may occur in transitive and intransitive clauses alike.

In (35), the adjective piin (white) is a resultative verb in an intransitive clause, and in (36), piir takes part as a transitive verb in a causative alternation rendering the meaning "whiten." In (37), the adjective man (red) appears in a transitive clause with the meaning "redden" (hence "bleach one's skin"). Note that man is subjected to distributive reduplication in an instance of verbal plurality that harmonises with the plural reference of the subject "women." The non-reduplicated form, man (to become red) is equally grammatical with plural subjects:

(35) Konja aa-kekeln piin.

NAME POSS-cloth be.white

"Konja's cloth is white."

(36) Gmakuuba pii-r u-yi-l.

NAME white POSS-head-CL.SG

"Gmakuuba has whitened his hair/Gmakuba whitens his hair."
Bi-pii-b
man-man bi-baa.
CL.PL-woman-CL.PL RED-red CL.PL-self

"Women have bleached their skin."

In view of the ambitransitivity and therefore very verbal behaviour of Type 3 adjectives, one may be tempted to view them as verbs tout court and reject their classification as adjectives. We have, however, already presented evidence for the adjectivehood of Type 3 items with respect to their distributional specificities vis-à-vis resultative/stative verbs. The latter cannot appear as modifiers in N-A compounds, whereas Type 3 adjectives can (see [26]-[27]).

Furthermore, when Type 3 adjectives are employed as verbal predicates, they undergo formal changes that primary verbs do not undergo. This is another reason why we consider the verbal function of Type 3 adjectives to be derived or secondary (Bhat 1999: 191; Croft 1991: 54). For example, the Type 3 adjectives kpok (old) in (38) and nyoo (deep) in (39) always appear with word-final segments (marked in bold) when used as verbs, irrespective of their tense-aspect specification. As far as we can tell, these 
segmental changes are idiosyncratic and not found with primary verbs, compare the verbs $b i$ (spoil) in (40) and doo (finish) in (41), which do not take on any additional segments in the corresponding contexts (cf. Bisilki and Yakpo 2019).

(38) Waa-loor ngbaan kpokl la. POSS.3SG-car DEM be.old DM "That car of his/hers is/has become old."

\begin{tabular}{|c|c|}
\hline$-l$ & $\begin{array}{ll}g \boldsymbol{a} & f i \\
\text { FUT } & \text { tom }\end{array}$ \\
\hline
\end{tabular}
$\begin{array}{lllll}\text { (40) } & \text { Waa-loor } & \text { ngbaan } & \boldsymbol{b i} & \text { la. } \\ \text { POSS.3SG-car } & \text { DEM } & \text { spoil } & \text { DM }\end{array}$ "That car of his/hers is spoilt."

(41) Ti-jiir tei ga doo dandaana. CL-food DEM FUT finish right.now "This food will be finished right now."

Only Type 3 adjectives occur as predicators of verbal clauses. Types 1 and 2 do not serve as predicate nuclei on their own in any context, hence the ungrammaticality of the two clauses below featuring the Type 1 adjectives sakpiin (big) and waatir (small) in (42) and the Type 2 adjective chain (clean) in (43).

(42) *Los wei sakpiin/waatir.

car DEM be.big/be.small

Intended: "This car is big/small."

$\begin{array}{lll}* \text { U-bo } & \text { wei } & \text { chain. } \\ \text { CL.SG-child } & \text { DEM } & \text { be.clean }\end{array}$

Intended: "This child is clean/neat."

By contrast, Type 1 adjectives can only occur as nominalised complements to the identity/equative copula ye (COP) in order to predicate properties (see [15]-[16]), while chain (clean), the only member of the Type 2 class, only occurs as an adjectival complement to the copula ye (see 6.3).

\section{The Distribution of Adjectives in Likpakpaln}

Table 1 presents a summary of the distributions and structural features of adjectives in Likpakpaln. The table shows that there are considerable distributional differences between groups of adjectives with respect to their use as predicates in verbal clauses, their occurrence as copula complements, and their use as attributive modifiers of nouns. Table 1 contains a list of the 21 adjectives we could identify in Likpakpaln. Although this list is probably not conclusive, we do not expect a much greater number of 
adjectives to emerge. The adjectives in Table 1 can be subdivided into three types in accordance with their distributional characteristics.

Table 1: Summary of Distributional and Semantic Features of Likpakpaln Adjectives

\begin{tabular}{|c|c|c|c|c|c|}
\hline Type & $\begin{array}{l}\text { Semantic } \\
\text { Class }\end{array}$ & Adjective & Verb & $\begin{array}{l}\text { Copula } \\
\text { Complement }\end{array}$ & $\begin{array}{l}\text { Noun } \\
\text { Modifier }\end{array}$ \\
\hline \multirow[t]{5}{*}{1} & Dimension & sakpiin/sakpen (big) & $x$ & $x$ & $\checkmark$ \\
\hline & & waatir (small) & $x$ & $x$ & $\checkmark$ \\
\hline & & gengey/gey (short) & $x$ & $x$ & $\checkmark$ \\
\hline & Value & bатэn (proper/real) & $x$ & $x$ & $\checkmark$ \\
\hline & Speed & suon (slow) & $x$ & $x$ & $\checkmark$ \\
\hline 2 & Property & chain (clean) & $x$ & $\checkmark$ & $x$ \\
\hline \multirow[t]{15}{*}{3} & Dimension & $f \supset f \jmath k / f \jmath k$ (long) & $\checkmark$ & $x$ & $\checkmark$ \\
\hline & & nyoo (deep) & $\checkmark$ & $x$ & $\checkmark$ \\
\hline & Age & kpok (old) & $\checkmark$ & $x$ & $\checkmark$ \\
\hline & & pэon (new) & $\checkmark$ & $x$ & $\checkmark$ \\
\hline & Value & nyaan/yan (good) & $\checkmark$ & $x$ & $\checkmark$ \\
\hline & Colour & bəmbon/bon (black) & $\checkmark$ & $x$ & $\checkmark$ \\
\hline & & pipiin/piin (white) & $\checkmark$ & $x$ & $\checkmark$ \\
\hline & & man/men/mamen (red) & $\checkmark$ & $x$ & $\checkmark$ \\
\hline & Property & рээ (hard) & $\checkmark$ & $x$ & $\checkmark$ \\
\hline & & mиап (sweet) & $\checkmark$ & $x$ & $\checkmark$ \\
\hline & & kuan (dry) & $\checkmark$ & $x$ & $\checkmark$ \\
\hline & & ton (hot) & $\checkmark$ & $x$ & $\checkmark$ \\
\hline & & $\operatorname{diin}(\mathrm{soft})$ & $\checkmark$ & $x$ & $\checkmark$ \\
\hline & & nyuun (heavy) & $\checkmark$ & $x$ & $\checkmark$ \\
\hline & & poo (strong) & $\checkmark$ & $x$ & $\checkmark$ \\
\hline
\end{tabular}

Type 1 adjectives may only occur as adjectival nouns with noun class affixes. In this case, they occur as nominal complements of the copula ye (see [15] and [16]). They may, therefore, appear neither in the slot of a copula complement bare of a noun class affix like the Type 2 item (see [30]) nor in a verbal slot like Type 3 items (see e.g. [35]). Type 1 items are, therefore, the most nominal of the items listed in Table 1. The onlybut crucial - characteristic that distinguishes Type 1 items from regular nouns is that they lack their own noun class markers and agree morphologically with the head of the $\mathrm{NP}$, even in copula structures.

The only Type 2 adjective is chain (clean), which may form a predicate with either of the two copulas ye (COP) or bi (COP.LOC) (see [30]). Chain does not appear in a verbal slot. It can modify a noun attributively, but this renders its meaning idiomatic. We have suggested that chain is a loan and therefore diverges from all other adjectives in its 
distribution. It is interesting that chain is the only item in our data that can be used as an adjectival copula complement bare of nominalising morphology. In Likpakpaln, this strategy appears limited to loan adjectives from e.g. Akan and English (see [33]). In combining characteristics of both verbs (they form part of the predicate) and nouns (they are more time stable than verbs and, therefore, require "copularisation" [Pustet 2003]), the Type 2 item chain is intermediate between a verb and a noun, as is typical of languages with large adjective classes like English.

Type 3 items constitute the bulk of adjectives in Likpakpaln. Unlike resultative/stative verbs, Type 3 adjectives can appear as modifiers in N-A compounds. They nevertheless share with verbs the feature of being able to constitute the predicate of intransitive and transitive verbal clauses (see [35]-[37]). With nouns they share the feature of taking noun class affixes when employed in a nominal function (see [19] and [20]). Type 3 items may not occur as copula complements. En gros, Type 3 items are therefore markedly more verbal than Type 1 and Type 2 items. At the same time, they also fall short of functioning as independent nouns. As with Type 1 items, the noun class affixes of Type 3 items always agree with those of the head noun.

In sum, the notion of adjective class in Likpakpaln is a scalar one, in which the three Types can be situated along a continuum ranging from more nominal to more verbal in nature. The existence of such clines in individual languages has been confirmed by typological research (Givón 1979; Pustet 2003).

\section{Conclusion}

Likpakpaln is a language with a small adjective class, consisting of about 20 members. Adjectives are distinguishable from the nominal and verbal word classes on morphosyntactic and semantic grounds. However, the distinction is not discrete but scalar, with a majority of adjectives leaning towards the verbal side (Type 3 ) and a minority of adjectives being rather nominal (Type 1). A single adjective (Type 2) seems to be a loan and displays the exceptional behaviour of appearing in the complement slot of the two Likpakpaln copulas. We do not claim, however, that this count is complete. Our data collection was based on the "universal" adjective classes and individual members identified by Dixon (2010a), and did not include ideophones, for example.

Further evidence in support of Likpakpaln as a language with a small adjective class, apart from the low number per se, is that it completely lacks adjectives of human propensity (cf. Ameka 2001; Dixon 2010a). On Dixon's (2010a) cross-linguistic scale, Likpakpaln can be identified as a Type $c$ language whose adjectives share grammatical properties with nouns and verbs to varying degrees. Similar observations regarding adjectives bearing either or both nominal and verbal properties have been made for the Mabia languages Dagbani, Gurene, and Kusaal. See Olawsky (1999; 2004) for Dagbani, Atintono (2013) for Gurene and Musah (2018) for Kusaal. 
This is the first study of adjectives in Likpakpaln, and accordingly, there is still much ground to be covered. In a next step, the ideophonic component of the lexicon deserves to be considered in detail. Likewise, the morpho-syntactic integration of (Akan, English, Dagbani, etc.) loan adjectives into copula clauses and other structures needs to be understood better. Finally, a thorough comparison of the properties of Likpakpaln adjectives with those of other Mabia languages could help to refine our understanding of the genetic and typological position of Likpakpaln in the Mabia family and the linguistic area covering both the Kwa and the Mabia languages of Ghana and neighbouring countries.

$\begin{array}{ll}\text { Abbreviations } \\ 1 & \text { 1st Person } \\ 2 & \text { 2nd Person } \\ 3 & \text { 3rd Person } \\ \text { ADV } & \text { Adverb } \\ \text { CL } & \text { (Noun) class marker } \\ \text { COP } & \text { Copula } \\ \text { DEF } & \text { Definite } \\ \text { DEM } & \text { Demonstrative } \\ \text { DM } & \text { Discourse marker } \\ \text { EMPH } & \text { Emphasis } \\ \text { FOC } & \text { Focus marker } \\ \text { FUT } & \text { Future } \\ \text { IDEO } & \text { Ideophone } \\ \text { INDP } & \text { Independent pronoun } \\ \text { LOC } & \text { Locative } \\ \text { NEG } & \text { Negative } \\ \text { NP } & \text { Noun phrase } \\ \text { PL } & \text { Plural } \\ \text { POSS } & \text { Possessive } \\ \text { RED } & \text { Reduplication } \\ \text { REL } & \text { Relative } \\ \text { SG } & \text { Singular } \\ \text { SID } & \text { Subject identity } \\ \text { TRM } & \text { Time reference marker }\end{array}$

\section{References}

Abubakari, H. 2018. “Aspects of the Grammar of Kusaal: Syntax-Information Structure Interface.” $\mathrm{PhD}$ thesis, University of Vienna. https://doi.org/10.25365/thesis.52565

Adouna, G. 2009. "Description phonologique et grammaticale du Konkomba - Langue Gur du Togo et du Ghana - Parler de Nawaré.” PhD Thesis, Université Rennes 2 and Université de Lomé. 
Agyekum, Kofi. 2013. “The Pragmatics of 'Mouth' Metaphors in Akan.” Ghana Journal of Linguistics 2 (1): 1-17.

Ameka, F. K. 2001. "Ideophones and the Nature of the Adjective Word Class in Ewe." In Ideophones, edited by F. K. E. Voeltz and C. Kilian-Hatz, 25-48. Amsterdam: John Benjamins. https://doi.org/10.1075/tsl.44.04ame.

Atintono, Samuel. 2013. "The Semantics and Grammar of Positional Verbs in Gurenc: A Typological Perspective.” PhD thesis, University of Manchester.

Bhat, D. N. S. 1994. The Adjectival Category: Criteria for Differentiation and Identification. Amsterdam: John Benjamins. https://doi.org/10.1075/slcs.24

Bhat, D. N. S. 1999. The Prominence of Tense, Aspect, and Mood. Amsterdam: John Benjamins. https://doi.org/10.1075/slcs.49

Bisilki, A. K., and R. A. Akpanglo-Nartey. 2017. "Noun Pluralisation as a Dialect Marker in Likpakpaln 'Konkomba.' " Journal of West African Languages 44 (2): 24-42.

Bisilki, A. K., and K. Yakpo. 2019. “A Dialect-Based Investigation of the Future Tense Marker in Likpakpaln (Konkomba).” Unpublished manuscript.

Bodomo, A. 1997. The Structure of Dagaare. Stanford: CSLI Publications.

Cahill, M. 2007. Aspects of the Morphology and Phonology of Konni. Dallas: SIL International and the University of Texas at Arlington.

Croft, W. 1991. Syntactic Categories and Grammatical Relations: The Cognitive Organization of Information. Chicago: University of Chicago Press.

Dakubu, M. E. K. 2005. Dagaare Grammar. Legon: Institute of African Studies.

Dixon, R. M. W. 1977. "Where Have All the Adjectives Gone?” Studies in Language 1 (1): 19-80. https://doi.org/10.1075/s1.1.1.04dix

Dixon, R. M. W. 1982a. "Noun Classes." In Where Have All the Adjectives Gone? and Other Essays in Semantics and Syntax, 159-183. Berlin: Mouton de Gruyter. https://doi.org/10.1515/9783110822939

Dixon, R. M. W. 1982b. Where Have All the Adjectives Gone? and Other Essays in Semantics and Syntax. Berlin: Mouton de Gruyter. https://doi.org/10.1515/9783110822939

Dixon, R. M. W. 2010a. Basic Linguistic Theory. Vol. 2, Grammatical Topics. Oxford: Oxford University Press.

Dixon, R. M. W. 2010b. Basic Linguistic Theory. Vol. 1, Methodology. Oxford: Oxford University Press. 
Dixon, R. M. W., and A. Y Aikhenvald, eds. 2004. Adjectives: A Cross-Linguistic Typology. Oxford: Oxford University Press. https://doi.org/10.1017/CBO9780511486241

Dorvlo, K. 2008. A Grammar of Logba (Ikpana). Utrecht: LOT.

Foley, W. A. 1991. The Yimas Language of New Guinea. Stanford: Stanford University Press.

Givón, T. 1979. On Understanding Grammar. New York: Academic Press.

Hasselbring, S. 2006. "Cross-Dialectal Acceptance of Written Standards: Two Ghanaian Case Studies." PhD thesis, University of South Africa.

Maasole, C. S. 2006. The Konkomba and Their Neighbours in the Pre-European Period up to 1914: A Study in Inter-ethnic Relations in Northern Ghana. Accra: Ghana Universities Press.

Meechan, M., and S. Poplack. 1995. "Orphan Categories in Bilingual Discourse:

Adjectivization Strategies in Wolof-French and Fongbe-French.” Language Variation and Change 7 (2): 169-194. https://doi.org/10.1017/S0954394500000971

Miehe, G., U. Kleinewillinghöfer, M. von Roncador, and K. Winkelmann. 2012. "Overview of Noun Classes in Gur (II)(revised and enlarged version)." In Noun Class Systems in Gur Languages. Vol. 2, edited by G. Miehe, B. Reineke and K. Winkelmann, 5-37. Cologne: Rüdiger Köppe.

Miehe, G., B. Reineke, and K. Winkelmann, eds. 2012. Noun Class Systems in Gur Languages: North Central Gur Languages. Cologne: Rüdiger Köppe.

Mpofu, N. 2009. “The Shona Adjective as a Prototypical Category.” PhD thesis, University of Oslo.

Musah, A. A. 2018. A Grammar of Kusaal: A Mabia (Gur) Language of Northern Ghana. Berlin: Peter Lang. https://doi.org/10.3726/b14344

Naden, T. 1988. “The Gur Languages.” In The Languages of Ghana, edited by M. E. Kropp, 12-49. London: Kegan Paul International for the International African Institute.

Nsoh, A. E. 2002. "Classifying the Nominal in the Gurene Dialect of Farefare of Northern Ghana." Journal of Dagaare Studies 2: 1-15.

Nsoh, A. E. 2011. "A Lexical-Functional Syntax of the Adjective in the Farefare Language." PhD thesis, University of Ghana.

Olawsky, K. J. 1999. Aspects of Dagbani Grammar, with Special Emphasis on Phonology and Morphology. Munich: Lincom Europa.

Olawsky, K. J. 2004. "What Is a Noun? What Is an adjective? Problems of Classification in Dagbani." Journal of African Languages and Linguistics 25 (2): 127-148.

https://doi.org/10.1515/jall.2004.25.2.127 
Pustet, R. 2003. Copulas: Universals in the Categorization of the Lexicon. Oxford: Oxford University Press.

Saboba District Assembly. 2018. Composite Budget for 2018-2021: 2018 Programme Based Budget Estimate for Saboba District Assembly. Accra: Republic of Ghana.

Schwarz, A. 2009. "How Many Focus Markers Are There in Konkomba?” In Selected Proceedings of the 38th Annual Conference on African Linguistics: Linguistic Theory and African Language Documentation, edited by M. Matondo, Fiona Mc Laughlin and E. Potsdam, 182-192. Somerville: Cascadilla Proceedings Project.

Segerer, G. 2008. "Closed Adjective Classes and Primary Adjectives in African Languages." HAL-SHS. http://halshs.archives-ouvertes.fr/halshs-00255943

Simons, G. F., and C. D. Fennig. 2017. “Konkomba.” In Ethnologue: Languages of the World. 20th ed. Dallas: SIL International. Accessed July 12, 2017. http://www.ethnologue.com/20/language/xon/

Tait, D. 2018. The Konkomba of Northern Ghana: Edited from His Published and Unpublished Writings by Jack Goody. London: Routledge. https://doi.org/10.4324/9780429486241

Van den Berg, M., E. K. Amuzu, K. E. Essizewa, E. Yevudey, and K. Tagba. 2017. "Crosslinguistic Effects in Adjectivization Strategies in Suriname, Ghana and Togo." In Language Contact in Africa and the African Diaspora in the Americas: In Honor of John V. Singler, edited by C. Cutler, Z. Vrzic, and P. Angermeyer, 343-362. Amsterdam: John Benjamins. https://doi.org/10.1075/cll.53.15ber

Watters, D. 2002. A Grammar of Kham. Cambridge: Cambridge University Press. https://doi.org/10.1017/CBO9780511486883

Welmers, W. E. 1973. African Language Structures. Berkeley: University of California Press.

Yakpo, K. 2009. "Complexity Revisited: Pichi (Equatorial Guinea) and Spanish in Contact." In Simplicity and Complexity in Creoles and Pidgins, edited by N. G. Faraclas and T. Klein, 183-215. London: Battlebridge. 